DEMOGRAPHIC RESEARCH

VOLUME 31, ARTICLE 39, PAGES 1199-1228

PUBLISHED 14 NOVEMBER 2014

http://www.demographic-research.org/Volumes/Vol31/39/

DOI: 10.4054/DemRes.2014.31.39

Research Article

Mortality selection in the first three months of life and survival in the following thirty-three months in rural Veneto (North-East Italy) from 1816 to 1835

Leonardo Piccione

Gianpiero Dalla-Zuanna

Alessandra Minello

(C) 2014 Piccione, Dalla-Zuanna \& Minello.

This open-access work is published under the terms of the Creative Commons Attribution NonCommercial License 2.0 Germany, which permits use, reproduction \& distribution in any medium for non-commercial purposes, provided the original author(s) and source are given credit.

See http://creativecommons.org/licenses/by-nc/2.0/de/ 


\section{Table of Contents}

1 Introduction 1200

$2 \quad$ Theoretical background and previous results 1202

3 Data 1205

$4 \quad$ Preliminary results and methodological choices 1211

5 Results 1218

$\begin{array}{lll}6 & \text { Conclusions } & 1221\end{array}$

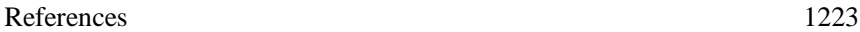




\title{
Mortality selection in the first three months of life and survival in the following thirty-three months in rural Veneto (North-East Italy) from 1816 to 1835
}

\author{
Leonardo Piccione ${ }^{1}$ \\ Gianpiero Dalla-Zuanna ${ }^{2}$
}

Alessandra Minello ${ }^{3}$

\begin{abstract}
BACKGROUND

A number of studies have examined the influence of life conditions in infancy (and pregnancy) on mortality risks in adulthood or old age. For those individuals who survived difficult life conditions, some scholars have found a prevalence of positive selection (relatively low mortality within the population), while others have observed the prevalence of a so-called scar-effect (relatively high mortality within the population).
\end{abstract}

\section{OBJECTIVE}

Using micro-data characterized by broad internal mortality differences before the demographic transition (seven parishes within the region of Veneto, North-East Italy, 1816-35), we aim to understand whether children who survived high mortality risks during the first three months of life (early infant mortality) had a higher or a lower probability of surviving during the following 33 months (late infant mortality).

\section{METHODS}

Using a Cox regression, we model the risk of dying during the period of 3-35 months of age, considering mortality level survived at age $0-2$ months of age as the main explanatory variable.

\section{RESULTS}

We show that positive selection prevailed. For cohorts who survived very severe early mortality selection $\left(\mathrm{q}_{0-2}>400 \%\right.$, where the subscripts are months of age), mortality

\footnotetext{
${ }^{1}$ University of Padua, Italy. E-Mail: piccione@stat.unipd.it.

${ }^{2}$ University of Padua, Italy.

${ }^{3}$ European University Institute, Italy.
} 
hazard of death during the following 33 months was 20\%-30\% lower compared to the cohorts where early mortality selection was relatively small $\left(\mathrm{q}_{0-2}<200 \%\right)$.

\section{CONCLUSIONS}

This result points to a homeostatic mechanism: mortality variability among the cohorts is, for $\mathrm{q}_{0-35}$, half that of the mortality variability for both $\mathrm{q}_{0-2}$ and $\mathrm{q}_{3-35}$.

\section{Introduction}

The issue examined in this paper can broadly be described as follows:

Many period-specific influences during life may affect mortality at a later stage, although it is often unclear which direction the resulting influence will take. For example, epidemic experiences or conditions of famine early in life may so debilitate a cohort that it subsequently experiences higher death rates relative to earlier or later cohorts. Others, however, argue that high mortality experienced in early life selects out the frail members of the cohort, resulting in reduced subsequent mortality (Hobcraft and Gilks 1984, p. 264, quoted in Billari and Rosina 2000, p. 2015).

While the two effects may coexist within the same situation, we can only measure the final balance within a population (Preston, Sill, and Drevenstedt 1998; Quaranta 2013). A number of papers attribute the influence of life conditions in infancy (and pregnancy) on mortality risks during adulthood or old age: while some authors find a prevalence of insult accumulation, others observe positive selection. ${ }^{4}$ If the events experienced in utero and during the first years of life influence mortality risks many years later, the same dynamic could be present, and perhaps even stronger, between contiguous periods. We study the effect of mortality selection during the first three months of life (from here on 'early infant mortality') on mortality in the 33 months that followed (from here on 'late infant mortality'). We aim to understand whether children who survived strong mortality risk during the first three months of life were 'positively selected' (i.e., they had a higher probability of surviving during the following 33

\footnotetext{
${ }^{4}$ See e.g., Caselli and Capocaccia 1989; Kannisto, Christensen, and Vaupel 1997; Preston, Sill, and Drevenstedt 1998; Bengtsson and Lindström 2000, 2003; Doblhammer 2004; Shkolnikov 2012; Ekamper et al. 2013; Quaranta 2013. See also Bruckner, Catalano, and Smith 2013; Helgertz and Bengtsson 2013; Shen and Zeng 2013 (papers presented at session 249 Pathways to health: direct and indirect effects of early life conditions on later health, at the IUSSP Conference of Busan, South Korea, on August 2013).
} 
months) or if rather they experienced a so-called scar-effect, i.e., a process of insult accumulation prevailed such that they had a lower probability of surviving during the following 33 months. ${ }^{5}$

We consider children born in Veneto (North-East Italy), using micro-data from the archives of seven parishes for the period 1816-1835, before the decline in mortality which characterized the demographic transition. The old demographic regime in Veneto provides an excellent context for studying this issue in that, as we will see below, there were considerable differences in early infant mortality, both across different areas of the region and especially across seasons. This intense variability makes it possible to identify, in detail, the possible influence of early infant mortality on mortality during the following 33 months.

The idea of examining the connections between early and late infant mortality builds on our previous research. Dalla-Zuanna and Rossi (2010), using aggregate data on the mortality of children within the 19 regions of the Austro-Hungarian Empire for the cohort born in 1851, show that in the Länder where mortality was high in the first three months of life there was relatively low mortality in the successive periods. Up until the $36^{\text {th }}$ month of life the association between $\mathrm{q}_{0-2}$ and $\mathrm{q}_{3-35}$ (where the subscripts are months, as elsewhere in this article) was negative, albeit moderate $(\mathrm{r}=-0.35$, see Figure 1). In the Habsburg Empire of the mid-1800s there was a kind of compensation between early infant mortality and mortality in the following months, what we describe as the prevalence of positive selection. In this work we are going to similarly assess whether such an effect exists within a smaller territory, studied with a much greater degree of detail thanks to the availability of individual data.

\footnotetext{
${ }^{5}$ In this paper we define early infant mortality as mortality risk during the first 3 months of life (age 0-2 months), and late infant mortality as mortality risk from the $4^{\text {th }}$ to the $36^{\text {th }}$ month of life (age 3-35 months). The idea is to focus on two age intervals that differ with regard to the causes of death: mortality after the $3^{\text {rd }}$ month of life should only be slightly affected by birth shocks or endogenous weakness, and mainly by exogenous causes (Bourgeois-Pichat 1951). Data on causes of death written in the death registers of our database (even if rough, see footnote 9) partially support the choice of using the end of the $3^{\text {rd }}$ month as a breakpoint between early and late infant mortality: during the $4^{\text {th }}$ month of life, two causes of death strongly related to birth ('spasm' and 'asthenia') drop to $39 \%$ of deaths compared to $62 \%$ for children who died during the $1^{\text {st }}$ month, $64 \%$ in the $2^{\text {nd }}$ month, and $59 \%$ in the $3^{\text {rd }}$ month. We do not consider children who died over the age of 3 because - as we describe in the data section - the mechanism of linking birth and death records becomes more uncertain as age at death increases.
} 
Figure 1: Probability of dying (\%o) during months 0-2 and 3-35 in the nineteen Länder of the Austro-Hungarian Empire for the cohort born in 1851

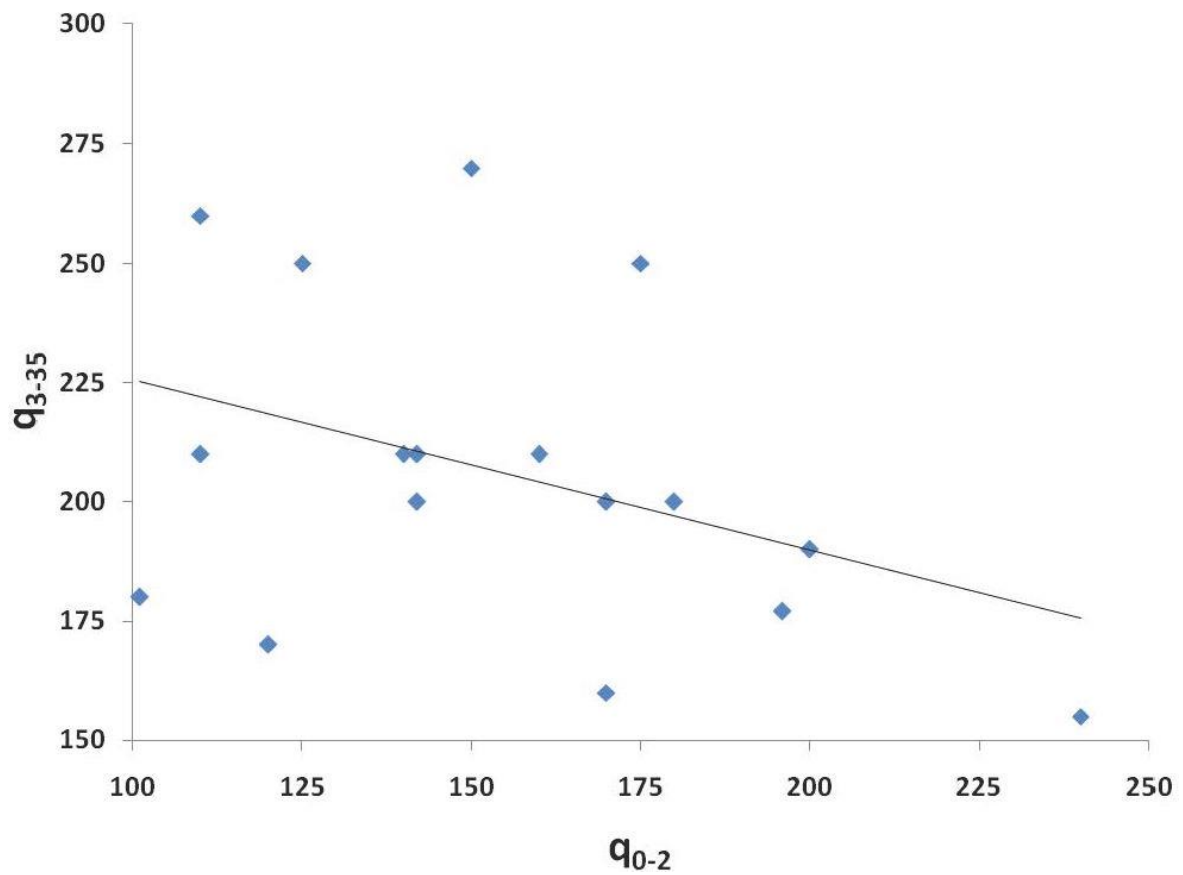

Source: Dalla-Zuanna and Rossi 2010.

\section{Theoretical background and previous results}

The issue of selection has already attracted the attention of scholars from various fields of study. When thinking about selection it is impossible not to refer to Charles Darwin and his theory of evolution. In Darwin's theory, natural selection certainly plays a fundamental role. Yet a further reading of Darwin suggests that his idea of natural selection also included more than mortality. Mortality selection is indeed a specific case of natural selection; it is a directional positive selection that favours "the fittest" (Endler 1986), i.e., people with the strongest probability of surviving. The selectionist argument, according to Peters (1991), is a logical truth and not a scientific theory per se. It is a very general concept that has been employed by different disciplines, from economics to epistemology. Demographers might very well benefit from knowledge gained by developments in sciences like biology and biomedicine. For example, Carey 
(1997) aimed to demonstrate the broad relevance of actuarial studies on Mediterranean fruit flies (medflies) to issues pertaining to humans. In turn, a number of researchers have used demographic selection arguments, with contrasting results, to explain the levelling-off of medfly mortality (Carey, Liedo, and Vaupel1995).

In population studies the notion of selection is often evoked to explain the demographic behaviour of migrant populations. For example, it has been suggested that low levels of mortality among migrants are the result of individuals who migrate being healthier and stronger compared to both those who did not emigrate and natives (the socalled 'healthy migrant effect', see e.g., McDonald and Kennedy 2004; Kennedy, McDonald, and Biddle 2006). A similar selection effect has been used to explain the marital and reproductive behaviour of immigrant couples and women (Goldstein and Goldstein 1983; Chattopadhyay, White, and Debpuur 2006).

With regard to mortality analyses, however, things are quite different, in that selection is not determined by an external event, as with migration, but by the same processes of elimination that apply to death. Demographers most often employ a selectionist approach to theories on ageing. As a population ages it simply becomes increasingly positively 'selected', as individuals with higher risk of death die sooner. The result is a population formed mostly by individuals with relatively low death rates (Carey and Liedo 1995a; Vaupel and Carey 1993; Vaupel, Manton, and Stallard 1979). When focusing on the older age groups, this concept helps to explain deviation of the human mortality trajectory from the well-known Gompertz function (Manton and Stallard 1996). Due to positive selection, the increase in mortality rates at older ages is slower than the $8 \%-10 \%$ per year observed in middle age.

Both the demographic and biological approaches share at least one common point when employing the notion of selection. If two identically heterogeneous populations have different levels of mortality, then changes in the mortality trajectory related to selection will occur at younger ages in the population with higher mortality, ceteris paribus (Carey 1997). Another example of positive selection has been observed for Swedish cohorts born during the $20^{\text {th }}$ century: the risk of ischemic heart disease mortality during cold periods drops among children who were in utero during a particularly cold period (Bruckner, Catalano, and Smith 2013). Positive selection has also been observed with regard to significant crises in mortality: the few available case studies on mortality before and after the plague epidemics that swept through Europe between the $14^{\text {th }}$ and the $18^{\text {th }}$ centuries verify this result. Following these plagues, people who survived epidemic outbreaks would have enjoyed higher survival rates than those before the plagues, although these results are somewhat controversial (Biraben 1975-76; Del Panta 1980; Billari and Rosina 1998, 2000; Alfani 2010). It is, in fact, difficult to discern whether the plagues swept away the weakest or if, alternatively, the smaller surviving populations (which may have been as much as $30 \%-50 \%$ less than 
before the plagues) relaxed Malthusian pressure, thanks to a higher ratio between resources and population. The lack of data, specifically on population during the centuries of plague in Europe, hinders further unravelling of the issue.

Other studies have shown the prevalence of the opposite effect: cohorts who survived serious mortality crises during the early years of life were also weaker later in life compared to cohorts slightly younger or older. For example, a process of insult accumulation occurred in Italy for male cohorts born in 1880-1899 who survived World War I: their mortality in adulthood and old age was slightly higher than that of their elder and younger 'brothers'; a consequence of diseases contracted during the war itself (Caselli and Capocaccia 1989; Caselli 1990). In southern Sweden during the $18^{\text {th }}$ and $19^{\text {th }}$ centuries, children who survived severe epidemics of smallpox or whooping cough, and severe nutritional stress, suffered higher levels of mortality as adults and in old age, particularly relative to airborne infectious diseases (Bengtsson and Lindström 2000, 2003). The same occurred with regard to Swedes born between 1912 and 1915 affected by the Spanish flu: exposure to the latter in the first years of life negatively affected both economic outcomes and health in old age. Health is also directly affected (not only indirectly via income and socio-economic position) (Helgertz and Bengtsson 2013; Quaranta 2013), and it has a long follow-up period, up to 70 years of age for cohorts born in Sweden during the $19^{\text {th }}$ and the early $20^{\text {th }}$ centuries. Quaranta (2013) finds positive selection for male birth cohorts suffering from high infant mortality, from age one up to about age 30, after which the scar-effect is greater than the selection effect. An increase of $12 \%$ in all causes of death between the ages of 18-63 was observed in the Western Netherlands among people born in 1944-1945 whose mothers were affected by the Great Famine during the first half of gestation, compared with those whose mothers were not so affected. This difference is considerable, and is greater compared to individuals whose fathers were employed in manual vs. nonmanual occupations ( $+8 \%$ for manual), and is independent of social class and education at age 18 (Ekamper et al. 2013). A similar dynamic also holds true for the cohorts most severely affected by the Great Famine of the 1930s or by World War II in Ukraine (Shkolnikov 2012). Other studies do not, however, show adult mortality differences between cohorts affected or not affected by famine during childhood (Kannisto, Christensen, and Vaupel 1997). The scar-effect has also been observed in China, among individuals born in the first half of the $20^{\text {th }}$ century. The total negative effect of adverse childhood conditions on current health is more prominent among the most elderly (aged 80+ in 2008-2009) compared to those who are slightly younger (aged 65-79, Shen and Zeng 2013). 


\section{Data}

We use unpublished nominal data drawn from $19^{\text {th }}$ century parish archives which form part of the IMAV project (Infant Mortality in Asburgical Veneto) based at the University of Padua's Department of Statistical Sciences. The aim of the project is to collect historical data that will aid in disentangling the main dynamics of the very high infant mortality that characterized the Veneto region during the Austrian Empire (18161866) (Derosas 2009; Dalla-Zuanna and Rosina 2011). During the $19^{\text {th }}$ century, Veneto was divided into about 50 districts. In order to have a reliable statistical sample of each economic, social, and territorial context, the IMAV project is in the process of collecting data from at least one parish in each district of the Provinces of Venice, Padua, Treviso, Verona, and Vicenza: the dataset will be completed in 2014. The data used in this paper come from the parochial archives of Agna, San Giorgio delle Pertiche, Chiesanuova and Urbana (Province of Padua), Carpenedo (Province of Venice), and Selva del Montello and Monastier (Province of Treviso) - see Figure 2. These seven parishes represent an extensive picture of the Veneto rural environment during the $19^{\text {th }}$ century. In the period of $1816-1866$, approximately 24,000 children were born in these seven parishes, 10,000 of whom died at ages 0-5 years during the period 1816-1870 (the role of parish priests as civil servants in filling out birth and death records continued during the years that followed the annexation of Veneto to the Kingdom of Italy in 1866 up until 1870).

From 1750-1840 the mortality of children in Veneto was extremely high, mainly due to mortality during the first month of life for children born during the winter ${ }^{6}$. During the eighty years that followed, mortality during the first year of life, and especially winter mortality during the first month, quickly declined (Dalla-Zuanna and Rosina 2011, see also Figures 3 and 4). While scholars have examined the demographic history of Veneto between the last stages of the ancien régime and the demographic transition (Pozzi 1991; Derosas 2002; Rosina and Zannini 2004), the patterns of high mortality during the first month of life remain far from explained. That said, there are clear indications that the influence of cold external temperatures was decisive (Derosas

\footnotetext{
${ }^{6}$ Levels of infant mortality equal to $350 \%$, such as those recorded in the Veneto region in the century of 1750 to 1850 , are very high, even if not exceptional in Europe before the health transition. For example, mortality during the first year of life was 486\% (1862-70), 502\%o (1871-75), and 444\%o (1879-88) in the Bavarian district of Augsburg, and 428\%, 471\%o, and 400\%o during the same three periods in the village of Anhausen, belonging to the same district, according to the family reconstruction by Knodel (1968, Table 3). However, the pattern of Bavarian parishes is not in line with the Veneto pattern, as mortality during the first month does not vary according to season (Knodel 1988, p. 62).
} 
2009; Dalla-Zuanna and Rosina 2011). ${ }^{7}$ The records employed here include birth and death registers filled out by the priests of each parish. These were then added to the 'traditional' registers of baptisms and burials as, during the Austrian Empire, priests were remunerated as civil servants, responsible for vital statistics. ${ }^{8}$ Records from the birth registers include the following information:

- date of birth

- given name of the child

- given and family name of the mother and father

- jobs of the mother and the father

- date of wedding

- date of the child's baptism.

Records from the death registers include:

- date of death

- given name of the child

- given and family name of the mother and father

- jobs of the deceased (or father for young children)

- place of birth

- age at death

- cause of death.

${ }^{7}$ According to regression models fitted by Dalla-Zuanna and Rosina (2011), a decrease of $1{ }^{\circ} \mathrm{C}$ in the minimum external temperature during the winter corresponded to a $5 \%$ increase in the daily risk of death during the first month of life. The daily risk of death during the third and fourth days of life varied from $80 \%$ to $130 \%$ to $220 \%$ if the minimum external temperature varied respectively from $+5^{\circ} \mathrm{C}$ to $0^{\circ} \mathrm{C}$ to $-5^{\circ} \mathrm{C}$.

${ }^{8}$ Church registers of baptisms from the mid- $17^{\text {th }}$ century on are widely available in the Catholic parishes of Veneto, while many burial registers can be found from the $18^{\text {th }}$ century on, although in many parishes these registers date even further back (e.g., in the two parishes of Adria, see Figure 2). Unlike the civil registers, the church records were not pre-printed, and as such are much more difficult to read. The data recorded in the ecclesiastical acts of baptism are similar to those recorded in the civil acts of birth. An important additional piece of information contained in the civil acts is the date of marriage, allowing us to identify children of the same parents without using the book of marriages, as would be necessary using only the church records. Moreover, the church records of baptisms do not - of course - report children who were not baptized (e.g., stillborns), as was the case in the civil registers. The information contained in the civil registers of death are also similar to those observed in the ecclesiastical burial records, although in the former cause of death is recorded in a much more systematic - although not complete - way. 
Figure 2: Location of the seven Veneto parishes considered in this study
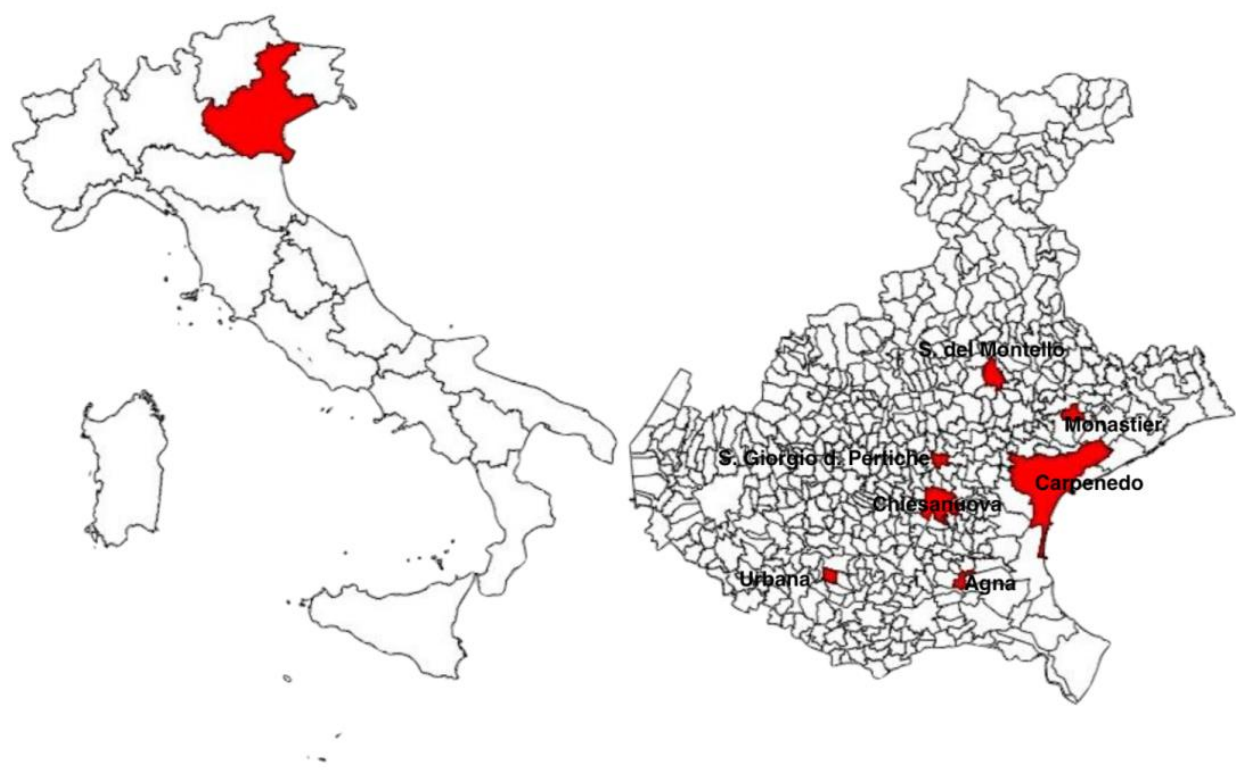

Figure 3: $\quad$ Secular trends in mortality rates during the first year of life (\%o) in some areas of Italy and in England, 1675-1900

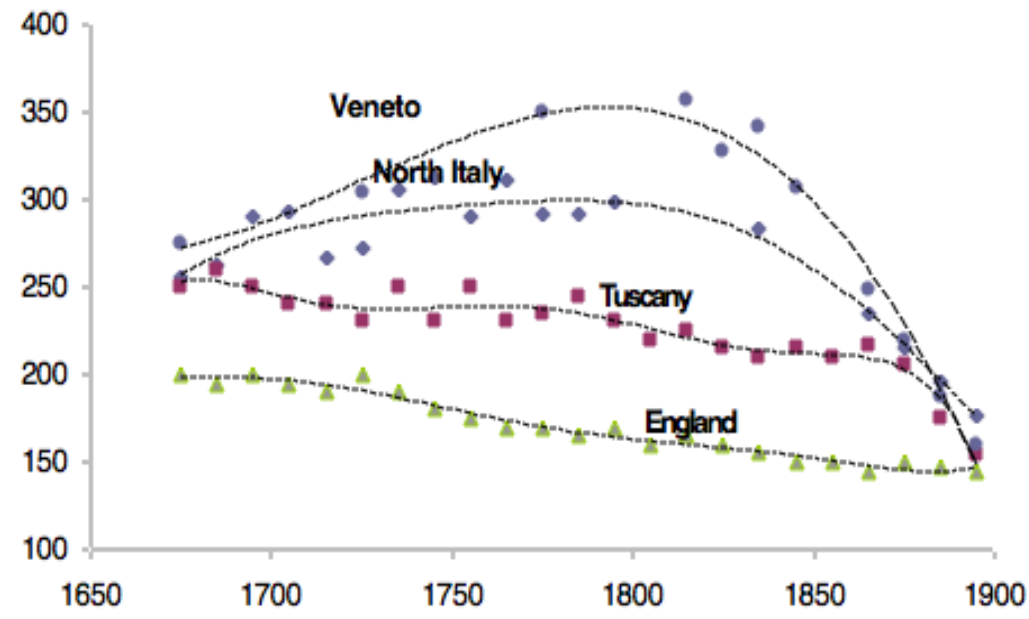

Source: Dalla-Zuanna and Rosina 2011. 
These registers were frequently checked by civil authorities (which was not the case for traditional ecclesiastic baptism and burial registers). They are very easy to use for demographic purposes as they are pre-printed and completed in a standardized way. We have linked birth certificates to death certificates for children born in the same parish who died at age 5 or younger, using as linkage keys name and surname of the child, name of the father, and name and surname of the mother. The linkage was facilitated by the availability of information on the children's age at death, as registered by priests; exact age was, however, ultimately calculated by matching the age at birth and death using Day Century Coding, or counting the number of days since January $1^{\text {st }}$, 1800 (Willekens 2013).

Pooling the seven parishes, more than $97 \%$ of children born in the same parish who died at age 5 or younger were linked to their birth certificate (Table 1). ${ }^{9}$ The linkage performance is even greater for children who died before their third birthday. When it was not possible to find the corresponding birth certificates for death certificates of children believed not to have been born in the parish after 1816, we 'generated' a birth record. More specifically, we indicated the date of birth starting from the age at death indicated by the priest on the death certificate. Using this system, we face a source of underestimation of mortality. The generated birth records make-up $2.44 \%$ of the total number of births, with some differences among parishes (see Table $1)^{10}$

\footnotetext{
${ }^{9}$ The no-linkage rate - which, as shown in Table 1, varies across the seven parishes - may depend on several factors: the accuracy of the parish priests in recording the events and the writing of the pastors themselves, but also the level of migratory exchanges of each parish. In fact, while our linkage procedure refers only to the deaths of babies born in the same parish, migration may have triggered more intense errors and potentially additional omissions (see the last column of Table 1 and the final part of this section).

${ }^{10}$ This procedure is similar to that used by Schofield and Wrigley $(1979$, p. 80, note 14) in reconstructing mortality in England during the $16^{\text {th }}$ and $17^{\text {th }}$ centuries through linking baptism and burial records. To avoid underestimating early mortality they create 'dummy births', i.e., children found in the burial registers who died in the first days of life "which cannot be linked to preceding baptisms, but clearly belong to a given family". Compared to the method used by Wrigley and Schofield, our approach may seem overly simplistic. However, it should be noted that the generated birth-records refer only to children who died in the first few years of life for whom we indicated, such as place of birth, the same parish in which they died. Consequently, our procedure - while perhaps causing a slight increase in the number of births due to a birth-record potentially already being present in the file - allows us to avoid underestimating child mortality.
} 
Table 1: Number of birth and death records under age 5 in the seven parishes, and some indices of linkage performance

\begin{tabular}{|c|c|c|c|c|c|}
\hline & Births (1816-66) & $\begin{array}{c}\text { Deaths before } \\
5^{\text {th }} \text { birthday } \\
(1816-70)\end{array}$ & $\begin{array}{c}\text { No-linkage rate } \\
\%(1816-70)\end{array}$ & $\begin{array}{c}\text { 'Generated' } \\
\text { births \% (1816- } \\
35)\end{array}$ & $\begin{array}{c}\text { Deaths at age 0- } \\
2 \text { years born } \\
\text { elsewhere \% } \\
(1816-35)\end{array}$ \\
\hline Agna (Padua) & 2,532 & 1,296 & 1.13 & 1.10 & 3.94 \\
\hline San Giorgio delle Pertiche (Padua) & 2,863 & 1,296 & 0.85 & 5.35 & 6.10 \\
\hline Chiesanuova (Padua) & 3,087 & 1,292 & 4.43 & 1.97 & 11.22 \\
\hline Urbana (Padua) & 2,425 & 1,020 & 1.25 & 0.77 & 13.73 \\
\hline Carpenedo (Venice) & 5,006 & 2,030 & 6.51 & 2.51 & 3.55 \\
\hline Selva del Montello (Treviso) & 2,981 & 1,215 & 2.77 & 1.97 & 0.41 \\
\hline Monastier (Treviso) & 4,828 & 1,777 & 3.38 & 3.30 & 1.86 \\
\hline Total & 23,722 & 9,926 & 2.90 & 2.44 & 4.02 \\
\hline
\end{tabular}

Mortality could also be underestimated due to systematic under-reporting of those children who died shortly after birth, as observed in other Italian and European contexts in similar or slightly earlier periods (see e.g., Dalla-Zuanna, D'Angelo, and Rosina 2003; Dalla-Zuanna and Rossi 2010). However, in our parishes the deaths of these children were seemingly recorded with a good level of accuracy, as our data are consistent with that observed in situations where data quality is considered good. Within our sample (limited to 1816-1835, see below), 5\% of the children are classified as having died within the first day of life; among this group, at least half could be stillborn as 52\% are nameless on the birth record (when it exists) and death record, while in $40 \%$ of cases the date of baptism is not reported on the birth record. As a result, both the stillbirth rate and mortality rate within the first day of life in the parishes considered here could be around 2\%-3\%, compatible with that suggested by Woods (2009) for the pre-transition health period. In addition, a 5\% probability of death in the first day of life in the period 1750-1810 was recorded for the sample of parishes used by the Cambridge Group in the reconstruction of the British population; as in our sample, stillbirths are included among the dead in the first day of life (Wrigley et al. 1997; Davenport 2010). In his analytical reconstruction of the population history of three Bavarian villages, Knodel (1970) found 2\% stillbirths during 1800-1849 while Oris, Derosas, and Breschi (2004, p. 362) show that during the $18^{\text {th }}$ and $19^{\text {th }}$ centuries the proportion of stillbirths was higher in protestant than in catholic contexts, suggesting that in the latter, 'false live births' (i.e., stillbirths baptized as live births in order to allow the baptism to take place) were more diffused. We cannot, of course, know for certain the 'true' values for stillbirths and mortality in the first day of life in 
the Veneto region in the early $19^{\text {th }}$ century. However, it seems difficult to imagine dramatic underreporting in our data. ${ }^{11}$

Finally our measures of mortality, which refer to the cohort ${ }^{12}$ born within a parish, could be underestimated due to emigration, as some of the children born in the parishes considered here could have died (at age 0-2 years) in other parishes, following the emigration of their parents. To better understand the extent of this underestimation we calculated the proportion of deaths at age 0-2 years, born in a parish other than the one studied (see the last column of Table 1). On average, this proportion for the seven parishes is around 4\%. If, for families with very young children, emigrations were similar in number to immigrations, it is possible that our measures of mortality are underestimated, and that these underestimations are greater where exchanges were more intense (as in Urbana and Chiesanuova) or lower where exchanges were less intense (as in Selva del Montello or Monastier). This issue should not, however, greatly affect our research goals in that the said underestimation should be similar, in relative terms, when and where early infant mortality was higher or lower.

${ }^{11}$ In the days following the first day of life, mortality in 1816-1835 in the 7 parishes under observation was very high (second day $=21 \%$, third day $=21 \%$; fourth day $=23 \%$; fifth day $=20 \%$; sixth day $=19 \%$; seventh day $=16 \%$ ): the probability of dying between the $2^{\text {nd }}$ and $7^{\text {th }}$ day of life was $114 \%$, four times higher than that observed in the aforementioned sample of English parishes (28\%) - Dalla-Zuanna and Rosina 2011. Neonatal mortality was even much higher than that observed at the end of the $20^{\text {th }}$ century in the poorest countries of the world, where the probability of dying in the first week of life (including the first day) was never higher than 45\% (Hill and Choi 2006), not far from that observed in some Indian contexts around 1970, but only for children with a weight at birth of 1500-2000 grams (Visaria 1988, p. 104). However, levels similar to that of Veneto were found in other European pre-transitional contexts. For example, in the above cited family reconstruction of several Bavarian villages (note 3), Knodel (1988, p. 48) finds that neonatal mortality (during the first month) ranged between $67 \%$ and $190 \%$; Goubert (1968) finds the level of neonatal mortality to be nearly $150 \%$ in some $18^{\text {th }}$ century French rural villages, 50\% higher than that observed in the white population of Quebec during 1621-1729 (Lalou 1997, p. 205). For additional reviews and comparisons see also Oris, Derosas, and Breschi 2004; Pozzi and Barona 2012. These high levels of mortality at ages 1-6 days might suggest an underestimation of mortality in the first day of life. However, since the 'discrepancy' between the first day and the following is observed only in the winter, and because - as illustrated in Figure 4 - the said 'discrepancy' is observed only for the period of 1750 to 1850 , our data could very well portray the true situation, i.e., 'abnormal' levels of mortality during the first week of life for children born during the cold season, with the exception of the first day. Finally, Dalla-Zuanna and Rossi (2010) - comparing the mortality of children in the 19 regions of the Austro-Hungarian Empire for the newborns of 1851 - show that in the (now) Italian and Austrian regions the under-registration of early deaths in birth and death registers (if present) was clearly at a much lower level than in Hungary and the Slavic Länder.

${ }^{12}$ The word 'cohort' is commonly used in demography to identify people who experienced the same demographic event within the same time-span (e.g., children born in the year t, marriages celebrated in the year t). In this article, 'cohort' is used in a broader sense, to identify children with identical characteristics at birth (e.g., newborns in the parish of Agna in the winter of years 1816-20; newborns in the parish of San Giorgio delle Pertiche in July of year 1832). 
Figure 4: Probability of death (\%o) during the first month of life by season of birth in the parish of Adria (in the province of Rovigo) in 1650-1900

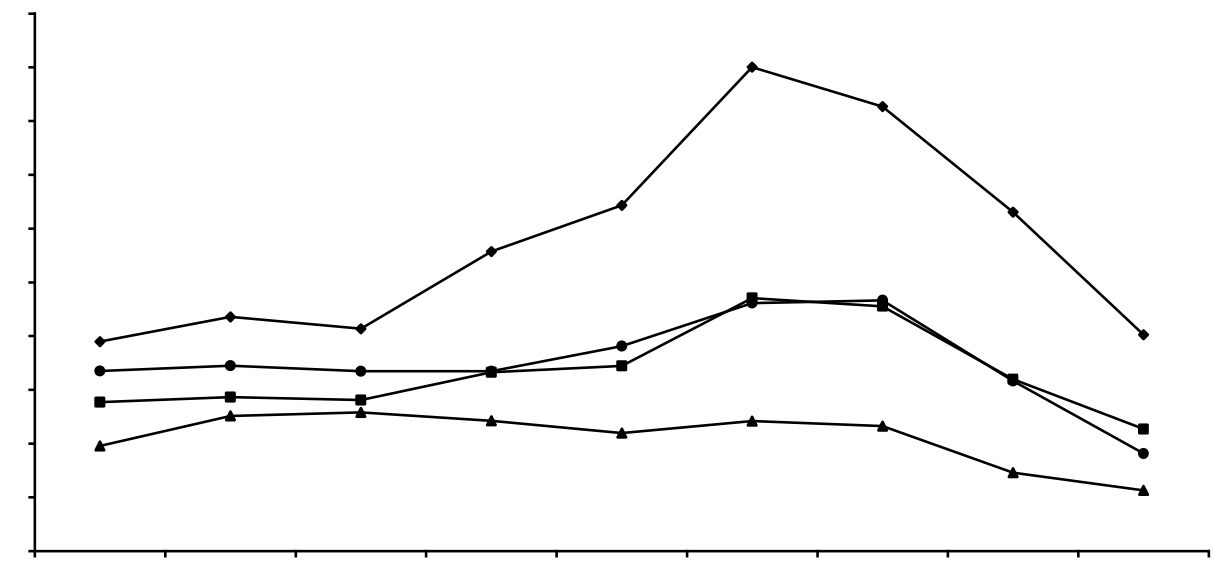

Source: Dalla-Zuanna and Rosina 2011.

\section{Preliminary results and methodological choices}

Figure 5 shows that the death probabilities $\mathrm{q}_{0-2}, \mathrm{q}_{3-35}$, and $\mathrm{q}_{0-35}$ in the pool of seven parishes are relatively constant until 1840 and then decline in the years that follow. As our aim is to study selection before the decline in mortality we include only the 8,809 children born during $1816-1835$ in our analysis. ${ }^{13}$

\footnotetext{
${ }^{13}$ In what follows we provide some additional information on data quality for the 8,809 children born in the seven parishes during 1816-1835. Sex is reported for all children but two, and the M/F sex ratio at birth is 1.07 , i.e., a value fully consistent with the sex ratio observed broadly for humankind. For only $1.5 \%$ of the children was it not possible to discern the job of the father $(85.4 \%$ farmer, $6.5 \%$ craftsman or belonging to the working class, $2.1 \%$ merchant, $3.3 \%$ servant, $1.2 \%$ employee, civil servant, or land owner). The low number of children belonging to last category (the 'wealthiest' group) made it impossible to use this variable for differential purposes. Cause of death was reported in $76 \%$ of the death records: this proportion grows notably with age (69\% for deaths at age 0-2 months, $87 \%$ for deaths at age 3-35 months). Moreover, causes are often confused with symptoms, as was common in death records dating from the $19^{\text {th }}$ century.
} 
Figure 5: Annual probability of death at ages 0-2, 3-35, and 0-35 months (\%o). Children born in seven rural parishes in the region of Veneto in 1816-68, and those dead in 1816-70

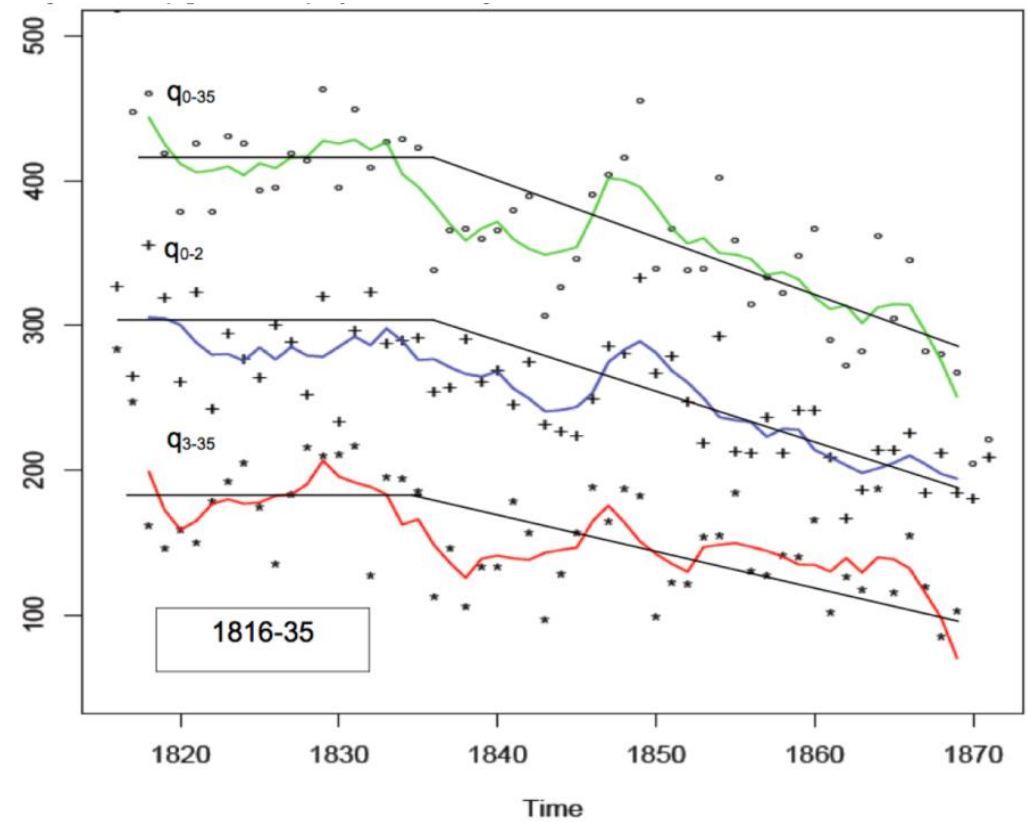

The crucial point is to find the 'key covariate', or the variable that describes the mortality level during the first three months of life, that can in turn be used to 'explain' the mortality risk of children who survived. Previous studies on the impact of temperature and climatic conditions on health reveal that winter mortality in Veneto was clearly higher than summer mortality, mainly during the early stages of life (Breschi, Derosas, and Manfredini 2000; Dalla-Zuanna and Rosina 2011). In our sample also, children born in the cold seasons were exposed to greater risk of death during the first month of life (Table 2 and Figure 6). Season of birth could thus be considered a proxy variable for early infant mortality risk. 
Table 2: Data on early and late infant mortality, according to select covariates. Children born in seven rural parishes in the region of Veneto during 1816-35

\begin{tabular}{|c|c|c|c|c|c|c|}
\hline & \multicolumn{2}{|c|}{ Months 0-2 } & \multicolumn{2}{|c|}{ Months 3-35 } & \multicolumn{2}{|c|}{$\begin{array}{c}\text { Probability of death (per } \\
\text { thousand) }\end{array}$} \\
\hline & $\begin{array}{c}\text { Birth } \\
\mathbf{a}\end{array}$ & $\begin{array}{c}\text { Dead } \\
\text { b }\end{array}$ & $\begin{array}{c}\text { Exposed } \\
c=a-b\end{array}$ & $\begin{array}{c}\text { Dead } \\
\text { d }\end{array}$ & $\begin{array}{l}q_{0-2} \\
b / a\end{array}$ & $\begin{array}{c}q_{3-35} \\
d / c\end{array}$ \\
\hline \multicolumn{7}{|l|}{ Season at birth } \\
\hline Winter & 1,968 & 861 & 1,107 & 190 & 438 & 172 \\
\hline Spring & 2,854 & 740 & 2,114 & 397 & 259 & 185 \\
\hline Summer & 2,137 & 393 & 1,744 & 360 & 184 & 206 \\
\hline Autumn & 1,850 & 556 & 1,294 & 222 & 301 & 172 \\
\hline \multicolumn{7}{|l|}{ Early infant mortality (calculated) } \\
\hline Low $(<200 \%)$ & 2,849 & 443 & 2,406 & 502 & 155 & 209 \\
\hline Medium (200-300\%o) & 3,001 & 757 & 2,244 & 416 & 252 & 185 \\
\hline High (300-400\%) & 1,626 & 586 & 1,040 & 162 & 360 & 156 \\
\hline Very high $(>400 \%$ ) & 1,333 & 765 & 568 & 89 & 573 & 157 \\
\hline \multicolumn{7}{|l|}{ Early infant mortality (estimated) } \\
\hline Low $(<200 \%$ o) & 3,000 & 466 & 2,534 & 515 & 155 & 203 \\
\hline Medium (200-300\%o) & 2,003 & 461 & 1,542 & 297 & 230 & 193 \\
\hline High (300-400\%) & 1,947 & 593 & 1,354 & 238 & 305 & 176 \\
\hline Very high $(>400 \%$ ) & 1,859 & 1,031 & 828 & 119 & 555 & 144 \\
\hline \multicolumn{7}{|l|}{ Sex } \\
\hline Female & 4,381 & 1,252 & 3,129 & 587 & 286 & 188 \\
\hline Male & 4,428 & 1,299 & 3,129 & 582 & 294 & 186 \\
\hline \multicolumn{7}{|l|}{ Period } \\
\hline $1816-20$ & 1,902 & 581 & 1,321 & 256 & 305 & 194 \\
\hline $1821-25$ & 2,437 & 679 & 1,758 & 319 & 279 & 181 \\
\hline $1826-30$ & 2,284 & 640 & 1,644 & 311 & 280 & 189 \\
\hline $1831-35$ & 2,186 & 651 & 1,535 & 283 & 298 & 184 \\
\hline \multicolumn{7}{|l|}{ Parish } \\
\hline San Giorgio delle Pertiche (PD) & 1,049 & 277 & 772 & 187 & 265 & 242 \\
\hline Chiesanuova (PD) & 1,159 & 295 & 864 & 197 & 254 & 228 \\
\hline Agna (PD) & 1,585 & 689 & 896 & 148 & 435 & 165 \\
\hline Urbana (PD) & 800 & 316 & 484 & 67 & 395 & 138 \\
\hline Carpenedo (VE) & 1,559 & 307 & 1,252 & 280 & 197 & 224 \\
\hline Selva del Montello (TV) & 1,028 & 321 & 707 & 92 & 312 & 130 \\
\hline Monastier (TV) & 1,629 & 346 & 1,283 & 198 & 212 & 154 \\
\hline$\overline{\text { Total }}$ & 8,809 & 2,551 & 6,258 & 1,169 & 290 & 187 \\
\hline
\end{tabular}


Figure 6: Early and late infant mortality (\%) by season of birth. Children born in seven rural parishes in the region of Veneto during 1816-35

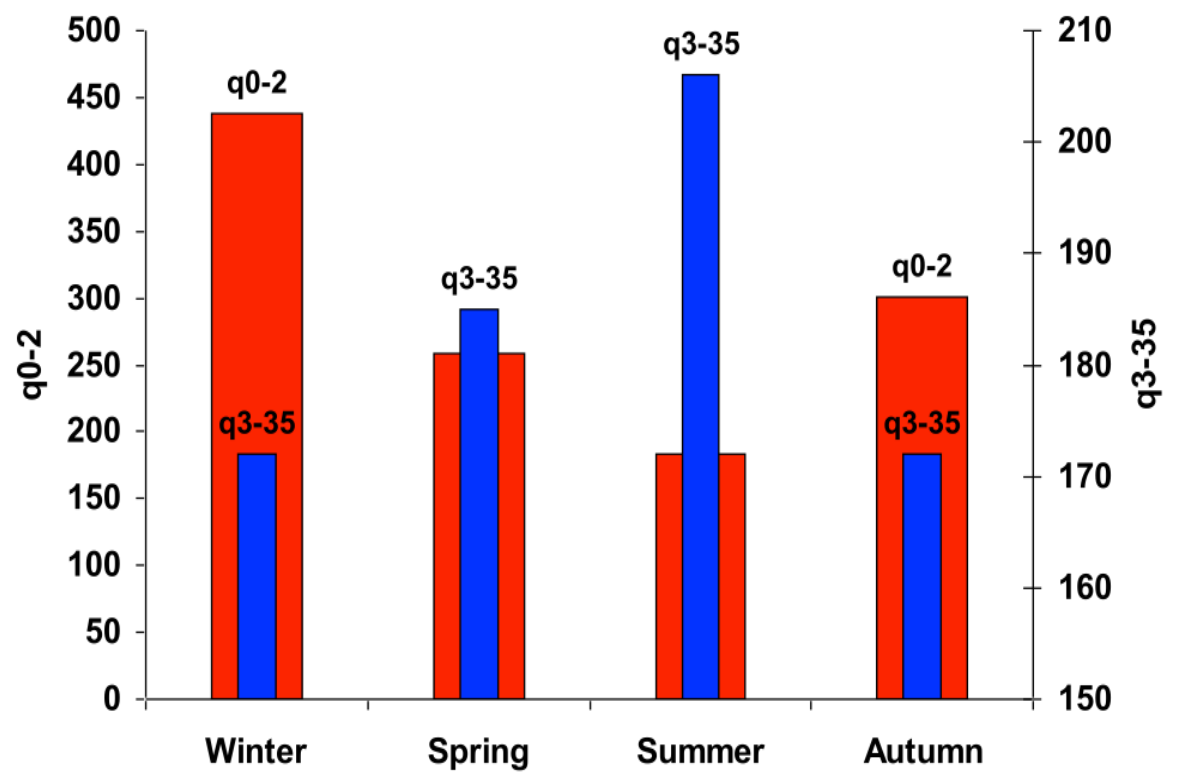

Figure 7 shows the probabilities of death within 3-month periods for the ages 3-35 months, pooling the seven parishes, according to season of birth (summer vs. winter). The shape of the two graphs is similar, dropping from month 3 to month 35 and peaking in the summer and autumn (mainly due to gastro-intestinal diseases). The general level of mortality during 3-35 months of age is, however, higher for children born in the summer, who survived a lower neonatal death risk compared to children born in the winter, who instead survived a higher neonatal death risk. 
Figure 7: The probability of death within successive 3-month age groups for those aged 3-35 months. Children who survived the first three months of life, born during winter (Dec, Jan, Feb) and summer (Jun, Jul, Aug) in seven rural parishes in the region Veneto during 1816-35

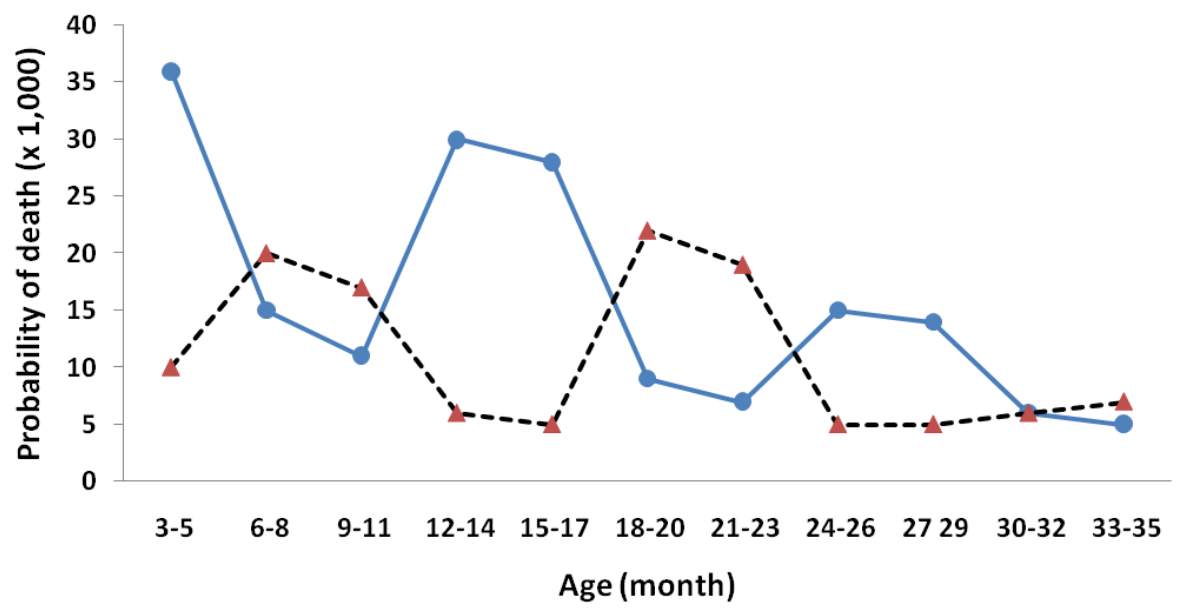

- Newborns in summer (mortality at age 0-2 month: 184\%o)

- - Newborns in winter (mortality at age 0-2 month: 438\%o)

While informative, the use of seasons is complicated by a scarcity of precise information on several aspects described in the literature as determinant in the definition of neonatal mortality in Veneto. A second option is thus the use of a more specific variable that combines season of birth with year of birth and parish of birth. These last two elements have in fact previously been shown to be relevant in the definition of mortality risk in Veneto (Dalla-Zuanna and Rosina 2011). We therefore decided to assign to each individual who survived the first three months the early infant mortality of his/her specific cohort. This designation was carried out in two different ways. First, we calculated 112 different levels of early infant mortality, provided by the combination of 4 seasons at birth, 4 groups of five-year intervals at birth, and 7 parishes of birth. Rates of mortality in the first three months of life range from 736\%o (cohort of children born during the winter in the years 1826-1830 in the parish of Urbana) to $104 \%$ (cohort of children born during the summer in the years 1826-1830 in the parish of Selva del Montello). The scattergram between early and late infant mortality for these 112 cohorts is shown in Figure 8. Finally, the 112 cohorts are pooled according to 
4 increasing levels of early infant mortality, and Figure 9 shows a clear bivariate inverse association between early and late infant mortality.

Figure 8: Early and late infant mortality for 112 cohorts provided by the combination of 4 seasons at birth, 4 groups of five-year cohorts at birth, and 7 parishes of birth. Children born in seven rural parishes of the region of Veneto during 1816-35

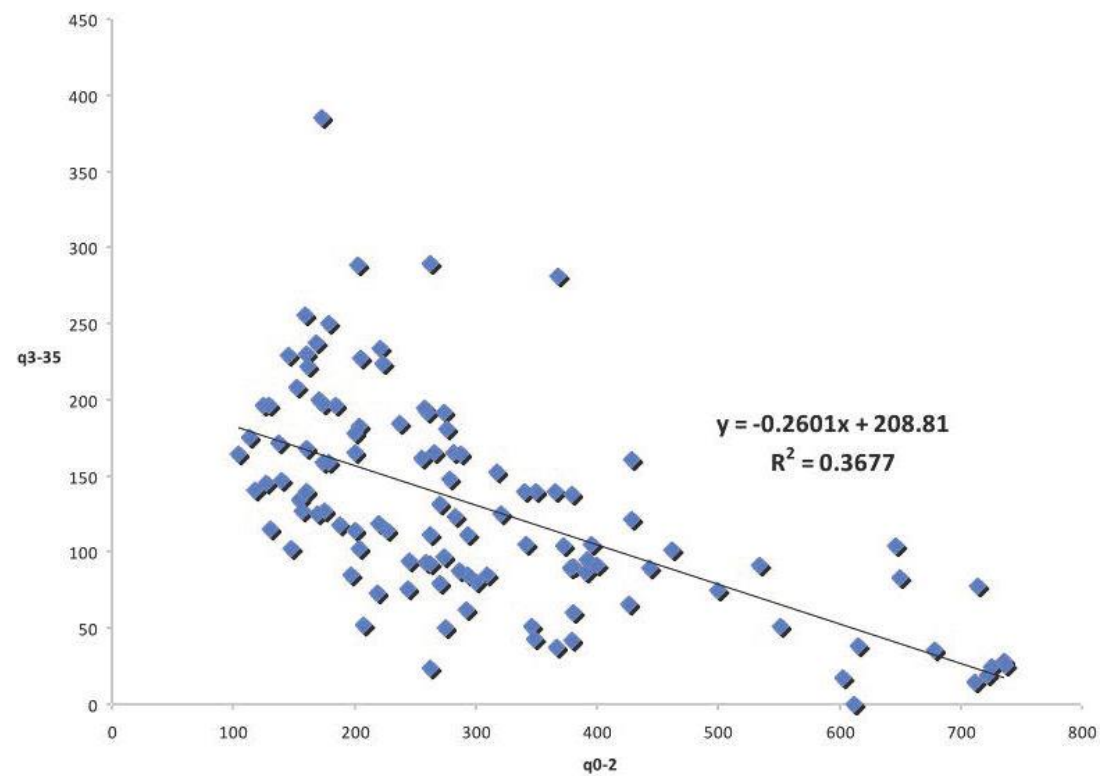

Using five-year intervals, parish and season may not be a precise enough measure to identify the specific environment a child experienced during his/her first three months of life. Early infant mortality could, for any number of reasons, vary from year to year or month to month, especially due to climate micro-oscillation. However, the number of children born in each year/season/parish is not large enough to calculate a stable measure of early infant mortality for smaller cohorts. To overcome this problem we estimated the 1,680 early infant mortality probabilities ( 12 months at birth, 20 years at birth, 7 parishes of birth) using the following logit regression model:

$q_{0-2}=\frac{\exp \left(\beta_{0}+\beta_{1} * f e b+\ldots+\beta_{11} * d e c+\beta_{12} * 1817+\ldots+\beta_{30} * 1835+\beta_{31} * S G d P+\ldots+\beta_{36} * \text { Monast }\right)}{1+\exp \left(\beta_{0}+\beta_{1} * f e b+\ldots+\beta_{11} * d e c+\beta_{12} * 1817+\ldots+\beta_{30} * 1835+\beta_{31} * S G d P+\ldots+\beta_{36} * \text { Monast }\right)}$ 
where $f e b$ and $d e c$ are months, 1817 and 1835 are years, $S G d P$ and Monast are the two parishes of San Giorgio delle Pertiche and Monastier; and the month of January, the year 1816, and the parish of Agna are the baseline.

Figure 9: $\quad$ Early and late infant mortality (\%). 112 cohorts $(7$ parishes $\times 4$ time periods $\times 4$ seasons) pooled according to the level of early infant mortality. Children born in seven rural parishes of the region of Veneto during 1816-35

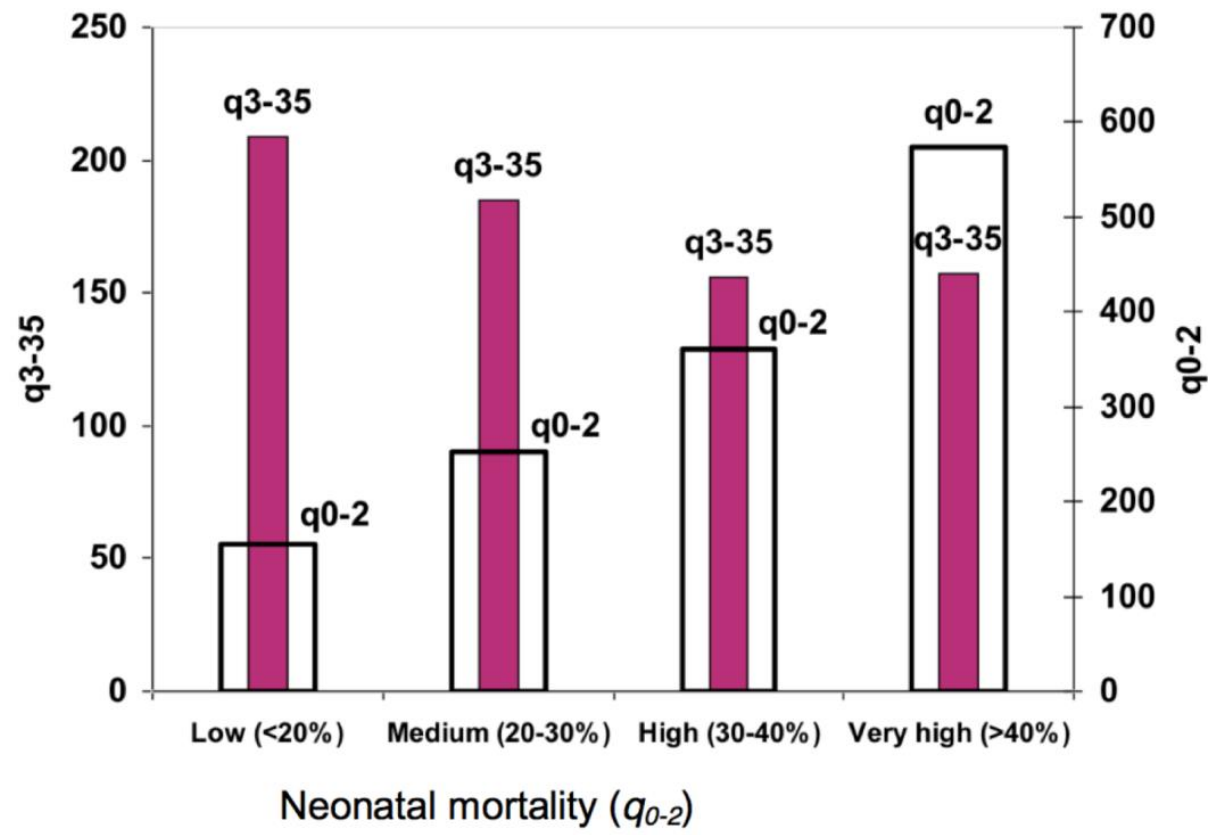

The results range from 734\% (cohort of children born in December of 1818 in the parish of Agna) to 64\% (cohort of children born in May of 1830 in the parish of Carpenedo) and potentially provide a more detailed and complete picture compared to using only a 'rough' measure of early infant mortality for a five-year interval.

We assigned the 'key covariates' to children who survived the first three months of life, together with several other variables from our dataset that may 'explain', at least partially, late infant mortality differences. In accordance with the literature - and given the preliminary results in Table 2 - we do not expect to observe large differences 
between the sexes in terms of late infant mortality. We similarly do not expect to see considerable differences in late infant mortality in the five-year intervals from 18161820 to $1831-1835$, as the downward trend in late infant mortality had yet to begin (see Figure 5). We expect, however, late infant mortality to vary according to parish of birth. Moreover, we expect late infant mortality to be higher during the summer, as suggested in Figure 6.

Our aim is to verify whether children who survived a context of high early infant mortality had lower or higher mortality in the following 33 months. As children who died during the months 3-35 are censored, one way to assess this question is a semiparametric Cox regression, which provides the monthly risk of death as a response variable, controlling for the elimination process (see e.g., Bruckner, Catalano, and Smith 2013; Ekamper et al. 2013). We model the risk of death between the $4^{\text {th }}$ and the $36^{\text {th }}$ months of life for individuals still surviving at the end of their $3^{\text {rd }}$ month, using the above-described covariates as explanatory variables. Our explanatory variables do not vary over time, with the exception of month of life, which has instead been taken into consideration by transforming our database into a person-period format. ${ }^{14}$

\section{Results}

The covariates included in the first five models are simply indices of early infant mortality (see Table 3): season at birth (Model 1), calculated early infant mortality (Model 2), early infant mortality estimated by logit regression model (Model 3), season at birth and calculated early infant mortality (Model 4), and season at birth and estimated early infant mortality (Model 5). In Models 4 and 5 - when early infant mortality is included - the association between season at birth and late infant mortality disappears. In addition, as season at birth and early infant mortality are strongly interrelated, the latter prevails in these two models. The 'goodness of fit' for Models 2 and 3 is better than the 'goodness of fit' for Model 1 (where season of birth is the only covariate). In light of these results, in the following models the 'season at birth' variable is not included and we perform two parallel analyses using calculated early infant

\footnotetext{
${ }^{14}$ Each individual now has a number of rows which correspond to the number of months lived. The last row corresponds to the month in which the subject died or is censored. We have associated each row with the relative season. For example, an individual born in May (season: spring) of 1816 who lived for 6 months has six rows in this new database format. The second row, in particular, indicates that the individual was alive in June (season: summer) of the same year. Notably, the last row indicates that the subject died in October (season: autumn) of 1816. In this way, it is possible to account for a possible effect of the transition from one season to another on the risk of death between the $4^{\text {th }}$ and the $36^{\text {th }}$ months of life.
} 
mortality and estimated early infant mortality as separate measures of selection during the first three months of life.

In order to determine whether selection during months $0-2$ provides additional explanation of mortality at ages 3-35 months, we measure whether the statistical performance of a 'basic' model (including only parish, time period, and sex) improves when early infant mortality is included as an explanatory variable.

Table 3: The risk of dying between the $4^{\text {th }}$ and the $36^{\text {th }}$ months of life by season at birth and early infant mortality, calculated or estimated. Cox model for children born in seven rural parishes of the region of Veneto during 1816-35

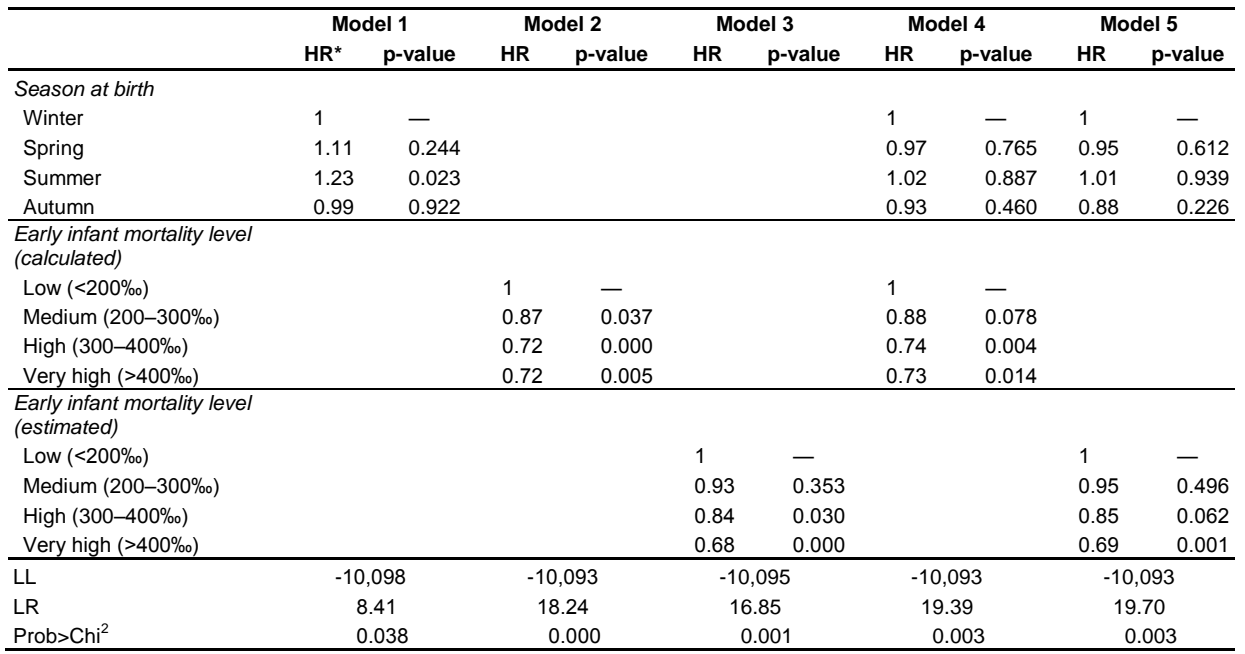

*HR: Hazard Ratio.

In the basic model the risk of death between the $4^{\text {th }}$ and the $36^{\text {th }}$ months of life is strongly related to parish, whereas sex and period do not influence the risk (Table 4, Model 6). When early infant mortality is added the performance of the model improves: including the calculated early infant mortality (Model 7) sees the 'goodness of fit' (loglikelihood) rise by $8\left(\mathrm{Chi}^{2}=16\right.$, d.o.f. $\left.=3, \mathrm{p}=0.001\right)$; including the estimated early infant mortality (Model 8) sees the 'goodness of fit' (log-likelihood) rise by $5\left(\mathrm{Chi}^{2}=10\right.$, d.o.f.=3, p=0.019). To summarise, the model is improved when calculated early infant mortality is used. After including early infant mortality in the model the rank of parishes does not change, showing that interaction between the two variables is weak. 
Table 4: Covariates of the risk of dying between the $4^{\text {th }}$ and the $36^{\text {th }}$ months of life for children who survived the third month of life. Two complete models with early infant mortality calculated or estimated ( 7 and 8); one model with a time-varying covariate (9). Cox model for children born in seven rural parishes of the region of Veneto during 1816-35

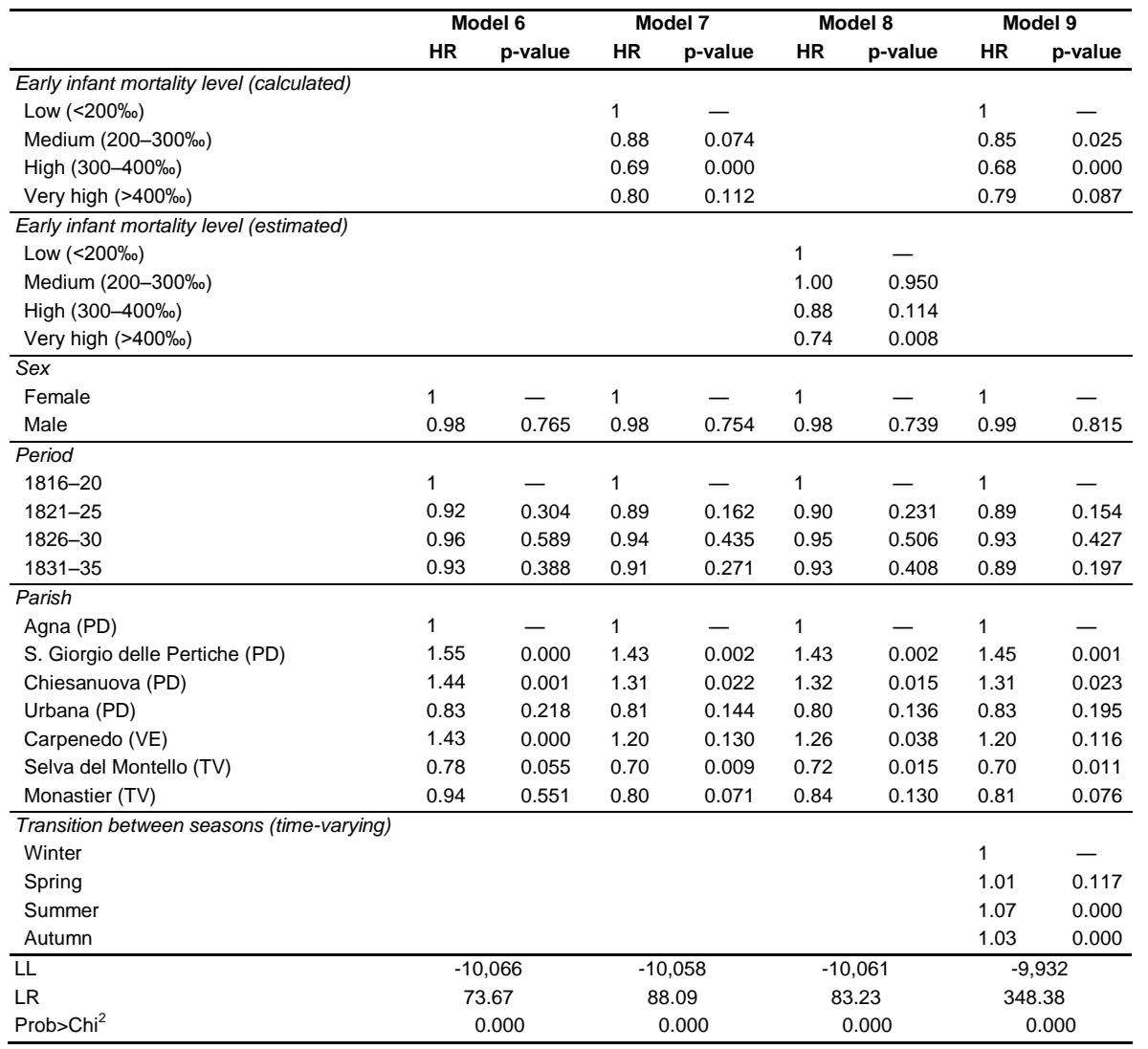

*HR: Hazard Ratio.

Model 9 introduces the transition between seasons as a time-varying covariate: when using winter as the baseline, the risk of dying during months 3-35 of life is significantly higher when there is a transition to a warmer season $(7.5 \%$ higher in the transition to summer compared to $3.3 \%$ in the transition to autumn), confirming the 
results of Figures 6, 7, and 9. This result is likely the outcome of the greater impact of gastro-enteric diseases during summer and autumn. ${ }^{15}$

\section{Conclusions}

The key result of this paper is that mortality selection during months $0-2$ may have played a significant role in determining differences in mortality during months 3-35 among cohorts born in seven rural Veneto parishes in the period 1816-1835, i.e., before the start of the mortality decline which formed part of the demographic transition. For children that survived a severe early infant mortality selection $\left(\mathrm{q}_{0-2}>400 \%\right.$, born mainly during winter), the hazard ratio of surviving the following 33 months was $20 \%-30 \%$ higher than that of children with relatively small early mortality selection $\left(\mathrm{q}_{0-2}<200 \%\right.$, born mainly during summer). This result suggests a sort of homeostatic mechanism, as mortality differences among the cohorts are lower for $\mathrm{q}_{0-35}$ than for both $\mathrm{q}_{0-2}$ and $\mathrm{q}_{3-35}$ : in considering the 112 cohorts obtained by crossing 4 seasons at birth, 4 five-year groupings at birth, and 7 parishes of birth, we observe that the variation coefficient $(\sigma / \mu)$ is 0.53 for $\mathrm{q}_{0-2}, 0.54$ for $\mathrm{q}_{3-35}$, but only 0.31 for $\mathrm{q}_{0-35}$.

These results are limited to the context of our study (Veneto in the early decades of the $19^{\text {th }}$ century), characterized by very strong mortality during the first week/month of life (excluding the first day), mainly for children born during the cold season. As we mentioned at the beginning of this article, while a scar-effect could coexist with positive selection, one predominates in different contexts and/or at different stages of life (even within the same cohort, as shown by Quaranta (2013) for Sweden). More generally, our results indicate the possibility that differences between cohorts in mortality during a given interval of age could also be due to differences in selection for death, for the same cohorts, during the age interval which immediately preceded.

This work provides several novel elements for the interpretation of differences in late infant mortality before the demographic transition. Many questions, however, remain unanswered, some of which could be addressed through our database. First, it would be interesting to find a more refined model for considering the selection process. Given that the predominating causes of death during the first few days of life were clearly quite different from those more common in the weeks that followed (Bourgeois-

\footnotetext{
${ }^{15}$ Cause of death is not always reported and is often confused with symptoms (see also footnote 8). However, by carefully examining death records at age 3-35 months, a cause of death likely identifiable as gastrointestinal disease is reported for 237 deaths (20.3\% of total), with tremendous seasonal differences (11 in winter, 17 in spring, 107 in summer, and 102 in autumn, which includes the relatively warm month of September).
} 
Pichat 1951), and the fact that the database contains the exact day of birth and exact day of death, it could be possible to consider narrower time spans and to measure, for example, whether the intensity of selection during the first week had an effect on the risk of dying during the subsequent weeks or months. Second, in order to disentangle territorial and environmental differences in late infant mortality, future research should focus on the characteristics of the environment in which each child tried to survive after overcoming the 'sieve' of the first weeks or months of life. Third, the selection procedure could be tested across different social strata, using the job of the father as recorded on the birth and death records. These three points will be reconsidered once the IMAV (Infant Mortality in Asburgic Veneto) sample of 50 parishes is complete, and thus a much broader group of rural and urban settings in the Provinces of Vicenza, Padua, Treviso, Venice, and Verona become available. Finally, it may be useful to more carefully consider the causes of death reported in the registers, especially for deaths occurring after the third month of life, so as to understand whether the higher mortality of children who were 'less selected' is due to any specific causes of death. 


\section{References}

Alfani, G. (2010). Il Grand Tour dei Cavalieri dell'Apocalisse: L'Italia del «lungo Cinquecento» (1494-1629). Venice, Italy: Marsilio.

Bengtsson, T. and Lindström, M. (2000). Childhood misery and disease in later life: The effects on mortality in old age of hazards experienced in early life, southern Sweden, 1760-1894. Population Studies 54(3): 263-277. doi:10.1080/71377 9096.

Bengtsson, T. and Lindström, M. (2003). Airborne infectious diseases during infancy and mortality in later life in southern Sweden, 1766-1894. International Journal of Epidemiology 32(2): 286-294. doi:10.1093/ije/dyg061.

Billari, F.C. and Rosina, A. (1998). Does cohort matter in pre-transitional mortality? An analysis of adult mortality using event history approach: the case of Chioggia in $17^{\text {th }}$ century. Genus 54(3-4): 327-347.

Billari, F.C. and Rosina, A. (2000). Analisi della mortalità alle età adulte e anziane: effetti di età, periodo e coorte. In: Rosina, A. and Rossi F. (eds.). Il sistema demografico alla fine delle grandi epidemie. Padua, Italy: CLEUP: 213-230.

Biraben, J.-N. (1975-76). Les hommes et la peste en France et dans les pays européens et méditerranéens. Paris, France: Mouton.

Bourgeois-Pichat, J. (1951). La mesure de la mortalité infantile. I. Principes et méthodes. Population 6(2): 233-248. doi:10.2307/1524151.

Breschi, M., Derosas, R., and Manfredini, M. (2000). Infant mortality in nineteenthcentury Italy: interactions between ecology and society. In: Bengtsson, T. and Saito, O. (eds.). Population and Economy. From Hunger to Modern Economic Growth. Oxford, UK: Oxford University Press: 457-489.

Bruckner, T.-A., Catalano, R., and Smith, K. (2013). Ambient temperature in utero and cold-related adult mortality in a Swedish cohort, 1915 to 2002. Paper presented at the $27^{\text {th }}$ IUSSP International Population Conference, Busan, South Korea, August 26-31 2013.

Carey, J.R. (1997). What demographers can learn from fruit fly actuarial models and biology. Demography 34(1): 17-30. doi:10.2307/2061657.

Carey, J.R., Liedo, P., and Vaupel, J.W. (1995). Mortality dynamics of density in the Mediterranean fruit fly. Experimental gerontology 30(6): 605-629. doi:10.1016/ 0531-5565(95)00013-5. 
Carey, J.R. and Liedo, P. (1995a). Sex mortality differentials and selective survival in med y cohorts: implications for human sex mortality differentials. Gerontologist 35(5): 588-596. doi:10.1093/geront/35.5.588.

Caselli, G. and Capocaccia, R. (1989). Age, period, cohort and early mortality: an analysis of adult mortality in Italy. Population Studies 43(1): 133-153. doi:10.1080/0032472031000143886.

Caselli, G. (1990). The influence of cohort effects on differentials and trends in mortality. In: Vallin, J., D'Souza, S., and Palloni, A. (eds.). Measurement and analysis of mortality. New approaches. Oxford, UK: Clarendon Press: 229-249.

Chattopadhyay, A., White, M.J., and Debpuur, C. (2006). Migrant fertility in Ghana: selection versus adaptation and disruption as causal mechanisms. Population Studies 60(2): 1-15. doi:10.1080/00324720600646287.

Dalla-Zuanna, G. and Rosina, A. (2011). An analysis of extremely high nineteenthcentury winter neonatal mortality in a local context of Northeastern Italy. European Journal of Population 27(1): 33-55. doi:10.1007/s10680-010-9219-5.

Dalla-Zuanna, G. and Rossi, F. (2010). Comparisons of infant mortality in the Austrian Empire Länder using the Tafeln (1851-54). Demographic Research 22(26): 813-862. doi:10.4054/DemRes.2010.22.26.

Dalla-Zuanna, G., D’Angelo, S., and Rosina, A. (2003). Massimo risultato con il minimo sforzo. Ricostruzione nominativa semi-automatica della sopravvivenza infantile e analisi del regime demografico di Alì (Messina) nel XVIII secolo. In: Breschi, M., Derosas, R., and Viazzo, P.P. (eds.). Piccolo è bello. Udine, Italy: Forum: 67-92.

Davenport, R. (2010). The relationship between stillbirth and early neonatal mortality: evidence from eighteenth century London. Paper presented at the 2010 BSPS Annual Conference, University of Exeter, UK, September 13-15 2010.

Del Panta, L. (1980). Le epidemie nella storia demografica italiana. Bologna, Italy: Loescher.

Derosas, R. (2002). Infant mortality broken into pieces: a case study on Venice in midnineteenth century. Società Italiana di Statistica, Atti della XLI Riunione Scientifica: $65-76$. 
Derosas, R. (2009). The joint effect of maternal malnutrition and cold weather on neonatal mortality in nineteenth-century Venice: An assessment of the hypothermia hypothesis. Population Studies 63(3): 233-251. doi:10.1080/00324 720903165449.

Doblhammer G. (2004). The late life legacy of very early life. Berlin, Germany: Springer. doi:10.1007/978-3-662-10349-4.

Ekamper, P., van Poppel, F., Stein. A.D., and Lumey, L.H. (2013). Independent and additive association of prenatal famine exposure and intermediary life conditions with adult mortality age 18-63 years. Social Science and Medicine 119: 232-239. doi:10.1016/j.socscimed.2013.10.027.

Endler, J.A. (1986). Natural selection in the wild. Princeton, NJ: Princeton University Press.

Goldstein, S. and Goldstein, A. (1983). Migration and fertility in peninsular Malaysia: an analysis using life history data. Santa Monica, CA: RAND Corporation.

Goubert, P. (1968). Legitimate fecundity and infant mortality in France during the $18^{\text {th }}$ century: a comparison. Daedalus 97(2): 593-603.

Helgertz, J. and Bengtsson, T. (2013). Lasting effects of the Spanish flu on income and health in later life. The case of Southern Sweden. Paper presented at the $27^{\text {th }}$ IUSSP International Population Conference, Busan, South Korea, August 26-31, 2013.

Hill, K. and Choi, Y. (2006). Neonatal mortality in the developing world. Demographic Research 14(18): 429-452. doi:10.4054/DemRes.2006.14.18.

Hobcraft, J. and Gilks, W. (1984). Age, period and cohort analysis in mortality studies. In: Vallin, J., Pollard, J.-H., and Heligman, L. (eds.). Méthodologies for the collection and analysis of mortality data. Liege, Belgium: Ordina Éditions: 245-264.

Kannisto V., Christensen, K., and Vaupel, J.W. (1997). No increased mortality in later life for cohorts born during famine. American Journal of Epidemiology 145(11): 987-994. doi:10.1093/oxfordjournals.aje.a009067.

Kennedy, S., McDonald, J.T., and Biddle N. (2006). The healthy immigrant effect and immigrant selection: evidence from four countries. SEDAP Research paper 164.

Knodel, J. (1968). Infant mortality and fertility in three Bavarian villages: an analysis of family histories from the $19^{\text {th }}$ century. Population Studies 22(3): 297-318. doi:10.1080/00324728.1968.10404941. 
Knodel, J. (1970). Two and a Half Centuries of Demographic History in a Bavarian Village. Population Studies 24(3): 353-376. doi:10.1080/00324728.1970.10406 134.

Knodel, J. (1988). Demographic behavior in the past. A study of fourteen German village population in the $18^{\text {th }}$ and $19^{\text {th }}$ centuries. Cambridge, UK: Cambridge University Press. doi:10.1017/CBO9780511523403.

Lalou, R. (1997). Endogenous mortality in New France. At the crossroads of natural and social selection. In: Bideau, A., Desjardins, B., and Brignoli, H. (eds.). Infant and child mortality in the past. Oxford, UK: Clarendon Press: 203-215.

Manton, K.G. and Stallard, E. (1996). Longevity in the United States: Age and sexspecific evidence on life span limits from mortality patterns 1960-1990. The Journals of Gerontology Series A: Biological Sciences and Medical Sciences 51A(5): B362-B375. doi:10.1093/gerona/51A.5.B362.

McDonald, J.T. and Kennedy S. (2004). Insights into the 'healthy immigrant effect': health status and health service use of immigrants to Canada. Social Science and Medicine 59(8): 1613-1627. doi:10.1016/j.socscimed.2004.02.004.

Oris, M., Derosas, R., and Breschi, M. (2004). Infant and Child Mortality. In: Bengtsson, T., Campbell, C., and Lee, J. (eds.). Life Under Pressure: Mortality and Living Standards in Europe and Asia, 1700-1900. Cambridge, Massachusset: MIT Press: 359-398.

Peters, R. (1991). A critique for ecology. Cambridge, UK: Cambridge University Press.

Pozzi, L. (1991). Evoluzione della mortalità e transizione sanitaria nelle province venete dall'unità agli anni Trenta. In: Rossi, F. (ed.). La transizione demografica del Veneto. Alcuni spunti di ricerca. Venice, Italy: Fondazione Corazzin Editrice: $151-181$.

Pozzi, L. and Barona, J. (2012). Vulnerable babies. Late foetal, neonatal and infant mortality in Europe $\left(18^{\text {th }}-20^{\text {th }}\right.$ centuries). Annales de démographie historique 123: $11-24$.

Preston, S.H., Hill, M.E., and Drevenstedt, G.L. (1998). Childhood conditions that predict survival to advanced ages among African-Americans. Social Science and Medicine 47(9): 1231-1246. doi:10.1016/S0277-9536(98)00180-4.

Quaranta, L. (2013). Scarred for life. How conditions in early life affect socioeconomic status, reproduction and mortality in Southern Sweden, 1813-1968. Lund, Sweden: Lund University (Lund Studies in Economic History 59). 
Rosina, A. and Zannini, A. (2004). Mortalità infantile. In: Dalla-Zuanna, G., Rossi, F., and Rosina, A. (eds.). Il Veneto. Storia della popolazione dalla caduta di Venezia a oggi. Venice, Italy: Marsilio: 177-194.

Schofield, R.S. and Wrigley, E.A. (1979). Infant and child mortality in England in the late Tudor and early Stuart period. In: Webster, C. (ed.). Health medicine and mortality in the sixteenth century. Cambridge, UK: Cambridge University Press: 61-96.

Shen, K. and Zeng, Y. (2013). The direct and total effects of childhood conditions on current health in oldest-old are stronger than that in young-old. Paper presented at the $27^{\text {th }}$ IUSSP International Population Conference, Busan, South Korea, August 26-31 2013.

Shkolnikov, V. (2012). Health crises and cohort mortality. In: Meslé, F. and Vallin, J. (eds.). Mortality and causes of death in 20th-century Ukraine. Dordrecht: Springer: 109-177. doi:10.1007/978-94-007-2433-4.

Vaupel, J.W. and Carey, J.R. (1993). Compositional interpretations of medfly mortality. Science 260(5114): 1666-1667. doi:10.1126/science.8503016.

Vaupel, J.W., Manton, K.G., and Stallard, E. (1979). The impact of heterogeneity in individual frailty on the dynamics of mortality. Demography 16(3): 439-454. doi: $10.2307 / 2061224$.

Visaria, L. (1988). Levels, trends and determinants of infant mortality in India. In: Anrudh, A.K. and Visaria, P. (eds.). Infant mortality in India. Differentials and determinants. New Delhi, India: Sage Publications: 67-126.

Willekens, F.J. (2013). Chronological objects in demographic research. Demographic Research 28(23): 649-680. doi:10.4054/DemRes.2013.28.23.

Woods, R. (2009). Death before birth: foetal health and mortality in historical perspective: Oxford, UK: Oxford University Press. doi:10.1093/acprof:oso/9780 199542758.001.0001.

Wrigley, E.A., Davies, R.S., Oeppen J.E., and Schofield, R.S. (1997). English population history from family reconstitution 1580-1837. Cambridge, UK: Cambridge University Press. doi:10.1017/CBO9780511660344. 
Piccione, Dalla-Zuanna \& Minello: Mortality selection in rural Veneto 